\title{
Biopharmaceutical Entrepreneurship, Open Innovation, and the Knowledge Economy
}

\author{
James J. Gillespie \\ jgillespie@saintmarys.edu | Faculty at Saint Mary's College, Department of Business and Economics, \\ Notre Dame, IN 46556 \\ Gregory J. Privitera \\ gprivite@sbu.edu|Faculty at St. Bonaventure University \\ Joseph Gaspero \\ Joseph@chisite.org|President at the Center for Healthcare Innovation
}

\begin{abstract}
This article focuses on the paradigm shift of the global biopharmaceutical sector's utilization of open innovation models to optimize drug development. Leveraging four exemplars, this review highlights that traditionally propriety, non-collaborative biotechnology and pharmaceutical companies increasingly use principles, processes, and structures of open innovation to increase drug R\&D effectiveness and efficiency. We discern three essential elements in the successful creation of open innovation partnerships: (i) culture, (ii) collaborative management skills, and (iii) strategic capability alignment. This analysis provides guidance for business leaders and scholars interested in the managerial and strategic dimensions of applying open innovation to the drug development environment. Theoretically, the article contributes to the growing stream of research integrating the concepts of knowledge economy, open innovation, and Enterprise 2.0. We discuss the specific ways in which open innovation holds potential to improve quality, increase speed, and lower costs and thus yield positive benefits for global health.
\end{abstract}

Keywords. Biopharmaceutical; Business Model Innovation; Knowledge Economy; Open Innovation.

Cite paper as: Gillespie, J., Privitera, G., Gaspero, J., (2019). Biopharmaceutical Entrepreneurship, Open Innovation, and the Knowledge Economy, Journal of Innovation Management, www.open-jim.org, 7(2), 59-77. 


\section{Introduction}

The knowledge economy is attaining preeminence in business and fundamentally altering managerial perspectives on corporate strategy, communication technologies, information access, and knowledge sharing. It is pushing managers toward business model innovation (BMI). Successful strategy development and implementation in the knowledge economy require a different set of managerial capabilities. In the new landscape, creating collaborative networks, effectively managing knowledge, and valuing intellectual capital are top priorities. Intangible assets are now an important indicator of national and organizational level performance (Del Giudice and Maggioni, 2014), and knowledge is a key competitive differentiator and vehicle for achieving increased firm performance (Del Giudice and Maggioni, 2014; Nicotra et al., 2014). Information technology is a core factor enabling organizations to design and implement effective knowledge management systems (Del Giudice and Della Peruta, 2016), which are increasingly essential for developing sustainable competitive advantages (Quintane et al., 2011).

Knowledge management has heightened importance because data, information, and knowledge are increasingly liquid, with relational reconfigurations emerging that challenge traditional organizational, industry, and societal hierarchies for business decision-making, value generation, and resource allocation (Del Giudice et al., 2016). The implications of the knowledge economy asserting itself are particularly profound for entrepreneurs and new ventures. The composition of a geographic region and its entrepreneurship ecosystem, as well as the institutional context, exert a strong influence on the creation, absorption, and dissemination of strategic knowledge by a new venture (Carayannis et al., 2016).

Along with relational reconfigurations, the knowledge economy also demands a reevaluation of an organization's business models. An organization requires a competitive value proposition and a functional business model, enabling the generation and capture of value, which can then be redistributed internally (e.g., to employees) and externally (e.g., to shareholders) (Carayannis, Grigoroudis et al., 2014). A firm's entrepreneurial activities are tools for any business model innovation and can be characterized as "strategic entrepreneurship" (Schneider and Spieth, 2013). For example, a company may leverage existing capabilities and competencies to launch a venture in a new geographic region (e.g., Brazil) or novel market space (e.g., biologics). While typically having to operate in environments characterized by substantial change, risk, and uncertainty, organizations are open systems seeking to balance consistency and stability with a business model (Carayannis, Grigoroudis et al., 2014).

Business models are more than just plans; they are fundamental drivers that help communicate, decode, and explain strategy, internally and externally (Carayannis et al., 2015). A firm's business model represents a concise conceptualization of how value is created (e.g., by developing a better, cheaper, or faster product), captured (i.e., monetizing the innovation), and allocated (e.g., rewarding the product development team with bonuses or additional stock options) (Johnson, 2010; Abdelkafi et al., 2013; De Reuver et al., 2013; Carayannis, Grigoroudis et al., 2014). BMI plays a crucial role stimulating an organization's level of excellence, resilience, and stability (Carayannis, Grigoroudis et al., 2014). As such, any BMI has a profound impact on organizational sustainability and the organization's stakeholders, including customers, employees, and partners (Carayannis et al., 2015). The normal environmental turbulence of economic, political, social, 
and technologic advances forces organizations to be responsive by adapting or even completely changing their business model or risk extinction (Chesbrough, 2010).

This paper examines BMI in the biopharmaceutical industry as firms turn to open innovation (OI) models of drug discovery. The biopharmaceutical, medical device, and pharmaceutical sectors have always been R\&D intensive, and the knowledge economy places an even stronger premium on data, information, and knowledge. The growing cost and length of drug discovery have generated political, regulatory, and strategic challenges, shaping new ways of thinking and managing. Enterprise 2.0 is fundamentally collaborative in generating intellectual capital, and biopharma firms are leveraging OI drug development to generate, organize, and share intellectual capital relating to $\mathrm{R} \& \mathrm{D}$ for new medicines. Based on our review of four key exemplars, we identify three essential elements for making this interfirm generating, organizing, and sharing process effective: (i) culture, (ii) collaborative management skills, and (iii) strategic capability alignment.

\section{Open innovation business model}

\subsection{OI defined and explained}

OI is a key business model innovation emerging in response to the knowledge economy. Chesbrough (2003) defines OI as utilization of external and internal ideas and pathways to create value. OI, as a form of co-opetition, is a new paradigm that purposively utilizes inflows and outflows of information and knowledge to accelerate internal innovation and to extend the markets for external use (Chesbrough, 2006). The modern open-source movement began in the early 1990s in Finland. A young university student named Linus Torvalds used the then novel Internet message board to post a free operating system with openly available source code others could add to. This innovative approach led to the creation of Linux and represented a fundamental shift in code development. The globally successful open-source software ecosystem provided an exemplar of OI via de-emphasis of intellectual property and decentralization of R\&D.

OI in the biopharmaceutical industry is a distributed and permeable development model, structure, and process driven by intentionally catalyzed and managed information and knowledge flows across organizational boundaries; the goal is the creation of new products or services, principally novel drugs, devices, or drug-device combinations (Chesbrough and Bogers, 2014; Nilsson and Minssen, 2018;). The key drug development stages amenable to OI are target identification and screening, tool compounds and preclinical studies, clinical trials, and initial post-FDA approval market entry. The Human Genome Project is an example of a long-standing, open scientific collaboration. OI is widely used in the consumer goods, electronics, and software industries (Gassmann et al., 2010). Much of OI operates informally, but it is increasingly integrated with regular, formal innovation practices (Wikhamn et al., 2016). OI could eventually become the new normal and is generating significant interest among policymakers, practitioners, and scholars (Chesbrough et al., 2014; Niosi and McKelvey, 2018; Schweizer and He, 2018; Toma et al., 2018).

With biopharmaceutical OI, multidisciplinary, multilayered, and multimodal innovation networks composed of government, universities, and industry (GUI) collaborate in creating, diffusing, and 
utilizing knowledge in nontraditional ways. (Carayannis and Ziemnowicz, 2007; Carayannis and Campbell, 2009). Although the primary generators of novel developments continue to be academically trained scientists operating in corporate or university facilities, there is a democratization of knowledge production (e.g., modeling the structure of certain proteins) via a dramatic increase in citizen science and open science innovation (Carayannis and Campbell, 2006).

\subsection{Competitive advantages of OI}

By creating strong interfirm networks, OI accelerates the advancement of medical science and helps deliver novel therapies to patients. OI also allows for the sharing of $R \& D$ costs, lowering the financial risk for any given partner, and extracting value from an external network of scientific and technology organizations. Participation in intellectual capital and knowledge sharing collaboratives increases an organization's ability to assess, monitor, and integrate new scientific and technological information (Carayannis, Del Giudice et al., 2014). For example, OI can facilitate sharing banks of clinical compounds ready for preclinical studies and for patients, as well as jointly identifying drug-like properties for novel compounds. OI can help researchers understand the causes and pathways of diseases and to identify potential targets for new drugs to intervene, with one key goal being to reduce repetition of assays, experiments, and clinical trials.

Across a variety of industries, data analytics is fundamentally altering business dynamics, and the biopharmaceutical industry is no exception. An inherent characteristic of OI is the leveraging of data from many sources: clinical trials, computer simulations, genomics, social media, and wearable devices. As artificial intelligence, big data, the Internet of Things, viral robots, and numerous other factors contribute to enormous growth in data, it is notable that data analytics is at the core of the OI approach to drug development.

Although OI as a biopharmaceutical BMI is still in the early stages of propagation, there is initial empirical evidence finding a positive link between OI and entrepreneurial growth. (Wikhamn et al., 2016). Not only does open science prove more efficacious in many cases, but also it is arguably a more ethical approach to biomedical research (Shaw, 2017). At a minimum, open scientific approaches can operate as a form of corporate social responsibility, generating positive reputational effects.

\section{Biopharmaceutical sector}

\subsection{R\&D intensive industry}

The biopharmaceutical sector is a knowledge-intensive industry, and in the broadest sense, it is defined as the application of medicine, science, and technology to alter organic and nonorganic materials for the enhanced production of knowledge, products, and services (Organisation for Economic Co-operation and Development, 2015). This paper focuses on the sector's production of regulatory approved drugs designed to improve human health and wellness. In this capacity, the industry generates and utilizes some of the most advanced science and technology available: advanced imaging, biomarkers, cell therapy, companion diagnostics, gene therapy, genomics, precision medicine, regenerative medicine, and sophisticated bioinformatics. This quality makes it an apt setting to study knowledge economy dynamics. 
Biopharma is a high-risk and high-reward industry, heavily reliant on intellectual property rights and patents. The prime modalities for R\&D collaboration include alliances, joint ventures, licensing agreements, mergers, and outsourcing. Structural forms of interorganizational collaboration have traditionally included agreements regarding licensing, manufacturing, marketing, $R \& D$, and technology transfer. Companies are evolving their business models away from the big blockbuster drug strategy to more collaborative and specialty product approaches (Schuhmacher et al., 2013), accompanied by aggressive pursuit of mergers and acquisitions. Large players such as AstraZeneca, GlaxoSmithKline, Johnson \& Johnson, Eli Lilly, Merck, Novartis, and Pfizer are assertively pursuing OI (Chesbrough and Chen, 2015).

Drug development is scientifically complex. Identification and validation of appropriate biomarkers are essential in commercial biotechnology, particularly with precision medicine. One reason why drugs fail during the discovery phase is inadequate therapeutic responses to novel biomarkers. Late stage failures of potential new medicines are costly and are best prevented with enhanced target identification and validation. The biological, pathophysiological, and physiological dimensions of biomarkers generate high complexity, often requiring combined expertise and skills beyond the domain of a given organization, even large biopharmaceutical companies. OI offers a promising way to address this innovation gap and increase the probability of biomarker success (Landeck, Lessl, Busch et al., 2016).

\subsection{Business and environmental challenges for biopharma}

Biopharmaceutical companies are among the most successful global business organizations, routinely ranking among the highest in gross revenues and profit margins. Even with this track record of financial achievement, the industry is not immune from the dictates of Enterprise 2.0 and the knowledge economy, so it is assertively turning to more collaborative management practices and network-oriented scientific development. The core drivers are a set of profound business and environmental challenges, many of which are unique to the biotechnology and pharmaceutical sectors.

The drug development process is expensive and lengthy. Bringing a new drug to market costs $\$ 2.6$ billion and takes about 12 years on average (Tufts Center for the Study of Drug Development, 2015). Total expenditures are significant; in 2016, for drug R\&D spending in the United States, National Institutes of Health accounted for about $\$ 30$ billion (U.S. Department of Health and Human Services, 2016) and industry accounted for about $\$ 50$ billion (Pharmaceutical Research and Manufacturers of America, 2016). Moreover, the process has a high failure rate. Even the most experienced executives and savviest scientists cannot predict with consistent accuracy which drugs will make it from computer models to FDA approval. The probability of gaining final regulatory approval is only $9.6 \%$ for drugs making it to Phase I (Biotechnology Innovation Organization et al., 2016). Perhaps most striking, the approval rate for Phase III drugs is only $60 \%$, yet by the time a drug reaches that stage, the company has probably invested hundreds of millions or even billions (US\$) in financial capital.

These drug development expenditures are eventually passed onto patients, thereby putting political and regulatory pressure on the industry to lower drug costs (Hartung et al., 2015; Howard et al., 2015). Established drug R\&D models are routinely critiqued as expensive, inefficient, and 
opaque, creating a business and scientific impetus to embrace new strategies (Paul et al., 2010; Munos, 2009, 2016; Shaw, 2017). During the early 2010s, the decreasing or stagnant pace of new drug discovery in the biopharmaceutical industry prompted many experts to call for disruptive innovation and radical changes to the existing paradigm (Paul et al., 2010; Munos and Chin, 2011; Scannell et al., 2012; Ekins et al., 2013). There was a positive trend line in the number of drugs developed by the industry that gained FDA approval: 27 in 2013, 41 in 2014, and 45 in 2015 (FDA, 2014, 2015, 2016), but the number slumped to 22 in 2016 (FDA, 2017).

Many experts continue to identify an increasing disparity between resource inputs (e.g., funding, lab space, researchers, scientific knowledge) and outcomes (e.g., new biological entities, new molecular entities) (Bowen and Casadevall, 2015). Since 1965, the numbers of scientific publications and article authors have increased $527 \%$ and $807 \%$ respectively (Shaw, 2017), yet the flow of drug approvals has not increased correspondingly. This has provided an additional impetus to develop drug production processes based on more collaboration, communication, and networking.

\subsection{Closed innovation evolving to open innovation}

The biopharmaceutical industry is highly proprietary, with corporate $\mathrm{R} \& \mathrm{D}$ centers often isolated and protected like fortresses. The modal model involves research completed within the legal, organizational, and physical boundaries of a vertically integrated corporation. R\&D proceeds in a secretive way in seeking regulatory approval (e.g., European Medicines Agency in the European Union, Food and Drug Administration in the United States, and Ministry of Agriculture, Forestry and Fisheries in Japan) for new biological entities (NBEs) and new molecular entities (NMEs) that are protected as firm-specific IP. Most of large pharma drug development still occurs through this more traditional, closed model. However, as noted, the current institutional processes for drug development seem recursive and unscalable surprisingly lacking in economics of scale or scope.

With the assertion of the knowledge economy, the closed innovation model, while still the dominant approach, is losing ground to more collaborative, open approaches. Large biopharmaceutical organizations increasingly seek to fill scientific and technology gaps through external innovation and embracing open approaches. To retain competitive advantages, these organizations are opening their innovation funnel. The industry is shifting from a model based on large, vertically integrated companies, conducting $\mathrm{R} \& \mathrm{D}$ in relative isolation, to more of an OI networked model, and companies are increasing the ratio of collaborative and outsourced drug development to in-house lab staff.

This trend is not entirely new. Knowledge clusters are an important dimension of OI drug development (Carayannis and Campbell, 2006), and biotechnology firms have long utilized clustering physically in formal and mostly informal ways similar to OI business models (Segers, 2015). This is prominent in certain geographies, such as Flanders and Wallonia in Belgium; Rhine-Neckar in Germany; and Cambridge, MA, San Diego, CA, and San Francisco, CA, in the United States. (Segers, 2016). Also, the industry has always maintained ties to academia and has long partnered with small and medium-sized enterprises (SMEs).

Despite a history of collaboration, biopharma has yet to embrace OI on a widespread basis. Part of this is attributable to the highly regulated nature of the biopharma industry, making 
it inherently resistant to change. Also, the successful financial track record of the sector as a whole means many companies feel no need to change business models. Other barriers to open strategies include cultural norms, IP concerns, and scientific complexities.

Nonetheless, the business imperative of the knowledge economy is forcing the fortress doors ajar, allowing for incorporation of Enterprise 2.0 approaches. SMEs that collaborate are now key drivers of drug development, accounting for most drugs currently in the development pipeline (Thomas and Wessel, 2015). These alliances are a win-win because, operating on their own, SMEs encounter many challenges, particularly in terms of designing and implementing clinical development initiatives (Moscicki and Tandon, 2017). Given the high-risk and capital-intensive nature of drug development, these small firms are especially subject to the liability of newness (Stinchcombe, 1965) and the liability of smallness (Freeman et al., 1983). There is also a growth in garage science start-ups and garage-bred innovation, as Enterprise 2.0 drug development pairs highly sophisticated global biopharmaceutical companies with amateur inventors and citizen scientists who provide a fresh scientific lens on drug development.

\section{OI in the biopharma ecosystem}

\subsection{Different business models and production processes}

The biopharmaceutical OI umbrella, as an industry-wide form of BMI, includes several mini-BMIs practiced to varying degrees by different institutions and organizations. These sub-innovations include big firm-SME collaboration, citizen scientists, crowdsourcing, data sharing, open sourcing, public engagement, pre-competition, and virtual $R \& D$. In the precompetitive research model, consortia collaborate to reduce R\&D duplication. Pre-competitive consortia in Europe and the United States include the Biomarkers Consortium, the Critical Path Institute's Predictive Safety and Toxicology Consortium, the Joint European Compound Library, the IMI's European Lead Factory, the Patient-Oriented Outcomes Consortium, and PrecisionFDA. These precompetitive collaborations yield gains for private, public, and NGO stakeholders in drug development. The virtual R\&D model involves a core group of scientists pursuing new drug development with help from external researchers who typically are not co-located and do not share organizational affiliation (Schuhmacher et al., 2013).

There are even model variations within the variations. Within the R\&D incubator model, some companies pursue a "strings attached" approach whereby incubator companies (typically SMEs) are required to sign licensing agreements with the host (typically a large, global biopharma company). In other cases, there are no legal obligations whatsoever, and the incubated company is commercially and legally free to utilize their IP in whatever way they deem most advantageous. Thus, there are dozens of distinct variations of OI drug development BMIs. Munos and Orloff (2016) delineate a helpful typology:

- "Pull" model where industry pulls new developments from external entities into its pipeline (e.g., Pfizer Centers for Therapeutic Innovation, the Novartis-Penn Center for Advanced Cellular Therapeutics)

- "Push" model where academia pushes to translate its bench lab developments into clinical candidates (e.g., Tri-Institutional Therapeutics Discovery Institute with partners such as 
Memorial Sloan Kettering Cancer Center, Rockefeller University, Takeda Pharmaceutical Company, and Weill Cornell Medical College)

- "Public-private partnership" model involving GUI collaborations (e.g., Alzheimer's Disease Neuroimaging Initiative, Biomarkers Consortium, Medicines for Malaria Venture, TB Alliance)

- "Risk-sharing" model where a large company, usually with future options to build or buy the scientific results, provides funding and other key resources to a small company with unique IP

These four models are frequently adapted and combined depending on the R\&D context, so there are a variety of mini-BMIs within the overall OI BMI paradigm. Ultimately, in the Enterprise 2.0 era, there is no "best" BMI appropriate for every drug development situation. Moreover, due to the normal economic cycles, changing consumer tastes, and technologic advancements, BMIs have a shelf life and must eventually be altered (Chesbrough, 2010).

\subsection{Application of OI and crowdsourcing to drug development}

All signs point to OI as a pathway to renew the industry's drug development process (Wikhamn et al., 2016). Rather than a full-scale widespread adoption, the biopharmaceutical industry is selectively utilizing open science models in different stages of the development process, including target identification, compound screening, clinical trials, and market launch. The industry has a tradition of embracing open science if one considers the publications of research studies in peer-reviewed medical and scientific journals. This represents a sharing of information with the epistemological community and the broader public, often at little or no cost to the consumer. However, this "openness" has fixed institutional parameters and historically does not extend to the research production process itself. Thus, the scale and type of open innovation currently underway by several companies are fundamentally different. Of course, within the biopharma industry, the OI model has enthusiasts, skeptics, and varieties of opinions between those two extremes, but consensus is trending toward OI.

OI platforms are premised on a collaborative approach linking scientific expertise, compound libraries, optimized molecules, services, technologies, and unique research tools. OI aims to stimulate collaboration among stakeholders who usually have divergent interests. As such, OI partnerships can be symmetric (e.g., collaborators are all large companies or all SMEs), asymmetric (e.g., big global pharma company paired with small biotech firm), or mixed (e.g., GUI consortium involving public, private, and NGO entities of all sizes). OI stimulates long-term value creation and multidirectional relationships between co-development collaborators (e.g., customers, suppliers, external researchers/scientists, governments, universities, and even competitors) and is characterized by a strong coevolutionary element (Del Giudice et al., 2015).

As an emergent tool in the Enterprise 2.0 era, OI is disruptive, and there is an interrelationship between disruptive business models, OI, regional systems of innovation, and technology clustering (Segers, 2015, 2016). OI drug development includes collaborative firms and their extended networks leveraging data and technology to generate, organize, and share knowledge to accelerate innovation in the scientific community. Breast cancer, malaria, and tropical disease are three of 
the more prominent clinical areas where open practices have thrived. Companies create awareness of their open network through a variety of methods, including social media, advisements in key journals, direct mailings to key thought leaders and scientific societies, and presentations at conferences. OI leverages the digital collaboration, social media, and social networking tools popular with Generation Y, and so it is sometimes characterized as a millennial approach to drug development.

Crowdsourcing, a type of OI using novel platforms, peer production, and virtual communities, is particularly associated with Generation Y and Generation Z. Jeff Howe and Mark Robinson, editors at Wired magazine, first coined the term crowdsourcing, and the original applications were in the business-to-consumer sector (Howe, 2008). Crowdsourcing is often done via the Internet with an open call to the community/crowd for assistance in providing a solution. To take one prominent example, Procter \& Gamble frequently invites consumers to provide ideas for novel household products or for improvements on existing goods (Procter \& Gamble, 2016). Crowdsourcing allows for the collection of many innovative ideas beyond the one selected. While its use in the drug development process remains in the infancy stage, crowdsourcing is an ascendant mini-BMI.

In particular, biopharmaceutical companies are leveraging crowdsourcing drug development for finding biomarkers and new molecular targets. Eli Lilly was one of the first companies to apply this approach via a platform called InnoCentive, which was eventually spun off as a separate entity that is now a community of over 200,000 experts in more than 20 countries (InnoCentive, 2017). The respondent selected by Eli Lilly as having the best solution is provided with a financial reward in exchange for transferring the IP. Bayer's Grants4Targets (G4T) initiative involves academic institutions applying for competitive grants in support of discovering novel drug targets (Bayer, 2017). Winning applicants are funded by Bayer to conduct focused experiments to provide further validation (or disconfirmation) of proposed biomarkers and targets, and Bayer makes available its own expertise in drug development and target validation. Crowdsourcing is a particularly interesting type of BMI within the new knowledge economy because it represents the combining of Enterprise 2.0 processes (e.g., peer production), structures (e.g., open competition and rewards framework), and tools (e.g., social media).

\subsection{Exemplars of Enterprise 2.0 biopharma collaboration}

Companies continue to explore new and innovative ways of partnering with academic institutions and with other biotechnology and pharmaceutical companies as they seek to increase the probability of delivering effective disease treatment. This collaborative research and sharing of intellectual capital across multiple organizations addresses the enlarged scale and scope of scientific, social, and technological challenges, with the GUI R\&D partnership being a prominent organizational example (Carayannis, Del Giudice et al., 2014). The goals of these collaborations are to accelerate medical science and to positively impact patients' lives. There are many potential permutations involving academic institutions, large pharmaceutical companies, small biotechnology companies, medical research charities, contract research organizations (CROs), and contract manufacturing organizations (CMOs).

Academic institutions and medical research charities are playing an enlarged role in all stages of 
drug development, from initial idea to early clinical development. For example, the Innovative Medicines Initiative (IMI) is a large public-private European partnership composed of large and small biopharmaceutical companies, hospitals, patient organizations, regulatory agencies, and research organizations with the goals of developing medicines faster and less expensively for patients (IMI, 2017). In the biomarker space, there are a growing number of successful collaborations between government, academia, and business (Asadullah et al., 2015; Landeck, Lessl, Reischl, et al., 2016). Below, four additional examples of important Enterprise 2.0 type collaborations currently underway in the field of drug development are considered. We selected these four examples after scanning dozens of other OI collaborations and consulting with several industry experts. These were ultimately selected because of their breadth, complexity, and success to date.

First, WIPO Re:Search is a global platform whose membership includes biopharmaceutical companies, academic institutes, and government research centers openly sharing IP property with the goal of accelerating drug development for neglected infectious diseases, including malaria and tuberculosis, which collectively afflict nearly 1.5 billion people. This Enterprise 2.0 oriented, cross-sector, multi-stakeholder program has proven highly successful in advancing product R\&D for these diseases. It now has more than 105 members from 30-plus countries, including large players such as Alnylam, Eisai, GlaxoSmithKline, Johnson \& Johnson, Merck KGaA, Merck (MSD), Novartis, Pfizer, Sanofi, and Takeda. All members of WIPO Re:Search agree to a guiding principle that any product developed will be provided to the 49 least-developed countries on a royalty-free basis. IP assets are shared for free among members, but users of another member's IP assets retain ownership to any IP they develop via WIPO Re:Search. Thus, this consortium strikes a nuanced balance between protecting IP rights, which provides an important financial inducement for participation, and encouraging free and open sharing, which provides the needed context for collaborative scientific advancement.

Second, Pistoia Alliance is a global, not-for-profit consortium of academic institutions, biopharmaceutical companies, publishers, and vendors. Created in 2009 during a conference in Pistoia, Italy, with AstraZeneca, GlaxoSmithKline, Novartis, and Pfizer as founding members, the alliance's mission is to transform the R\&D innovation model by stimulating precompetitive collaboration. There are now more than 80 members ranging from the aforementioned large life science conglomerates to several SMEs. In the knowledge economy spirit of overcoming shared organizational and scientific obstacles, the partners work to identify root causes of R\&D inefficiencies, develop best practices, and pursue technology pilots. Pistoia Alliance provides a legal framework to guide partnering efforts, acting as a roadmap and safety net for collaborative efforts. For example, even with its significant in-house resources, Pfizer had difficulty handling complex macromolecules computationally. It approached the Pistoia Alliance, which facilitated a collaborative project that successfully created an open-source standard bimolecular language called Hierarchical Editing Language for Macromolecules (HELM). HELM is now widely utilized by biopharmaceutical companies, regulatory agencies (e.g., FDA), and scientific publishers.

Third, Johnson \& Johnson (J\&J) has a state-of-the-art lab in La Jolla, CA, called JLABS focused on collaborative innovation that houses as tenants many current and potential J\&J competitors. J\&J created this "no strings attached" OI incubator in 2012 and has subsequently created 5 additional sites in North America. J\&J uses the JLABS concept to develop relationships with 
scientists and other innovators. Eventually, these companies can develop drug candidates or technology of interest to J\&J. Across its 6 JLABS, J\&J is currently incubating almost 150 companies. The tenants have access to J\&J's compound library, as well as its commercial and regulatory experts. JLABS staff assist the biotech entrepreneurs with attaining needed permits and ensuring environment, health, and safety standards. The subsidized rent for a lab space is a little over $\$ 1,000$ per month, only partially offsetting J\&J's overhead costs; this is a considerably less expensive option than investing $\$ 5-10$ million for an adequate start-up lab space. JLABS also conducts periodic competitions for early stage innovators, with winners being awarded free JLABS space. Tenants get access to many of the platforms and resources available to internal teams. Essentially, this allows for external entities to gain the advantages of closed innovation (e.g., legal expertise) within an OI construct.

Fourth, AstraZeneca's Open Innovation initiative encourages research partners at all stages of the $\mathrm{R} \& \mathrm{D}$ process to utilize its clinical compound bank, new molecule profiling, and pharmacology toolbox. Potential collaborators can access more than 250,000 current and discontinued compounds for screening. The initiative has received in excess of 400 proposals from researchers in nearly 30 countries, which has led to more than 150 collaborations. In addition, Compound Passport Service (CPS) is a platform produced by AstraZeneca to manage the shared access and rights implications of OI projects. The CPS provides a system to record and manage compounds throughout their life cycle to prevent, among other problems, the issue that arises if AstraZeneca mistakenly reveals IP subject to a proprietary legal agreement with a prior collaborator. Enterprise 2.0 structures create, develop, and distribute business-to-consumer(B2C) products and services by leveraging the latest innovation approaches and open-source principles. As shown by AstraZeneca's CPS platform, sometimes that output requires the creation of foundational business-to-business (B2B) frameworks crucial for effectively managing shared access and potentially overlapping IP. Thus, in the biopharma context, Enterprise 2.0 innovation yields two value-generating outputs: (i) novel $\mathrm{B} 2 \mathrm{C}$ goods/services (e.g., a new cure for brain cancer or breast cancer) and (ii) novel B2B frameworks/processes (e.g., software for managing and allocating IP rights).

Because of differences in institutional norms and organizational cultures, these Enterprise 2.0 partnerships are difficult to create and even more challenging to manage (Carayannis, Del Giudice et al., 2014). Abstracting across these examples, potential keys to creating a beneficial GUI collaboration include cultural fit, appropriate technology, external champions, internal champions, and long-term oriented risk capital. However, because each situation is so specific, there may not be a set formula for success (Carayannis, Del Giudice et al., 2014). Thus, one set of Enterprise 2.0 structures and tools may work in the open innovation development of Drug A, but another set might be better for OI development of Drug B. Moreover, in some cases (e.g., development of Drug C), Enterprise 2.0 and the knowledge economy notwithstanding, the best approach might be the traditional, highly proprietary, closed innovation pathway.

\section{Discussion and observations}

Several observations emerge from our examination of Enterprise 2.0, collaborative firms/networks, and the knowledge economy in the context of OI drug development. First, for OI drug develop- 
ment to be effective, the collaborating entities must have an open-minded culture to accompany the OI network. Collaboration is not a natural human or organizational behavior (Carayannis, Del Giudice et al., 2014). Thus, OI should include joint goal direction and open data, as well as permeable boundaries and communication transparency. Cultural resistance to OI is natural, and GUI collaborations typically fail because of cultural and managerial resistance, rather than for scientific or technical reasons (Carayannis, Del Giudice et al., 2014). In fact, OI does carry risks related to a collaborator's behavior, including impairing competitiveness by premature submission of publications, limiting commercialization by the ill-timed filing of patents, and outright theft of ideas and other IP (Alexy et al., 2009; Robertson et al., 2014). Thus, a certain measure of internal resistance is functional and protective of corporate interests, but fundamental cultural clashes, particularly when driven by one or more party's failure to fully embrace the OI ethos, can result in failure or severe underperformance (e.g., the collaboration produces no new medicines).

Second, OI requires the right collaborative management skills (e.g., communication, decisionmaking, and structure) for successful implementation.In terms of communication, because much of OI drug development is virtual, there is a heavy reliance on Enterprise 2.0 type digital communication and technology platforms to maintain connectivity and stimulate collaboration among geographically disbursed partners. In terms of decision-making, ideas generation, selection, and implementation, these functions need to become less hierarchical, with more of the key decisions deferred to researchers, scientists, and ground managers. In terms of structure, $m$ embers of an OI partnership should reach a priori agreement on the origin, ownership rights, and usage of compounds. As the OI business model has evolved, structural tools are emerging to facilitate open collaboration. The process of pairing companies with solution providers is becoming more efficient, reducing issues like rampant "window-shopping" (i.e., smaller potential collaborators previewing their ideas and technologies for large companies who ultimately decline to partner). New innovative workflow solutions are emerging for the management of IP concerns (e.g., AstraZeneca's CPS platform).

Third, strategic capability alignment is crucial. When interorganizational learning occurs in a global context, it requires organizations to acquire skills, implement structures, and develop novel and multiple forms of learning (Del Giudice and Maggioni, 2014). Because interorganizational collaboration is the core idea in open innovation (Levine and Prietula, 2013), capabilities for effectively developing interfirm trust are needed for this fast-changing $R \& D$ environment. With open networks as the foundation, executives must ensure that corporate strategy and firm capabilities are synced with BMI.

\section{Limitations and further research}

As with any examination of complex new business models, this article contained a number of limitations. First and principally, while a review piece approach has advantages (e.g., inclusion of rich, contextual elements), there are some inherent limitations on generalizability. We carefully selected the four exemplars explored, but that still represents a small subset of the hundreds of various types of OI biopharmaceutical collaborations currently underway globally. A limitation of the current article and an area for future research is undertaking a database-driven, quantitatively 
empirical analysis with a reasonably large N. The practical and statistical difficulty of such studies is that the unit of analysis is the collaboration itself, yet there are an enormous variety of biopharmaceutical OIs. This makes application of traditional quantitative methods challenging, yet this is an important and essential next step for this body of research.

Second, the article references ethical and legal considerations but does not explore these in any detail. Ethical and legal dimensions of open source biopharmaceutical developments are tremendously consequential - often of greater import than the pure scientific or strategic considerations. While delving into ethics or the legal/regulatory aspects of OI would unduly expand the scope of the article, they are crucial dynamics that have been the subject of entire articles and merit further research. Third, the article makes several references to regulation, which is clearly an important consideration given the highly regulated nature of the pharmaceutical industry. However, whereas the article generally presents regulation as a barrier, regulatory agencies, officials, and rules can also serve as crucial enablers of an increasingly open innovation world. Thus, future research could address this limitation by viewing regulation less descriptively (e.g., as a barrier to OI) and more normatively and prescriptively (e.g., how could and should regulation enable increased OI drug development).

There are additional key directions for future research. As alluded to, the application of OI to the normally highly competitive, propriety drug development space is sufficiently new and infrequent that assessing efficacy is not yet amenable to large $\mathrm{N}$ longitudinal data analyses, so that remains an area for subsequent examination. Moreover, the lengthy average time to develop a drug (often 10-12 years) creates a long lag between the use of OI drug development and final successful outcomes (e.g., regulatory approval). However, once there is sufficient data, it will be important to undertake longitudinal quantitative analyses comparing different models of OI to different R\&D outcomes. Building on classic work by Bass (1969), ongoing research explicates the process by which knowledge-sharing technologies diffuse within an ecosystem of potential adopters (Della Peruta and Del Giudice, 2013), but there is a need for more long-term oriented quantitative, empirical work on the role of value chain networks (e.g., competitors, complementors, customers, regulators, suppliers) in BMI and how members of that network can impact outcomes.

Another direction for future research is a focus on more of the specific collaboration and communication tools OI partners are leveraging for knowledge sharing. What social media and technology platforms are most effective for stimulating and supporting R\&D partnering? How does the application of social networking tools affect governance and performance of a GUI collaboration? When and how are social networking sites used for crowdsourcing and other efforts to bring together otherwise disparate researchers? Addressing these questions related to utilization of Enterprise 2.0 tools, as well as future quantitative analyses comparing R\&D inputs with new medicine outputs, would illuminate how OI collaborative firms and networks impact management research and practice regarding the global biopharmaceutical industry.

\section{Conclusion}

The growth in collaborative networks and interfirm partnering has profound implications for management research and practice. As the knowledge economy asserts itself, BMI can enhance 
learning and yield adaptive outcomes. Key tools in this regard include collaborative technology platforms, digital communication, OI (e.g., crowdsourcing), peer production, and social media. We applied these developments in OI, the knowledge economy, and Enterprise 2.0 to the setting of the biopharmaceutical industry and four specific exemplars. In particular, we examined the utilization of OI drug development to make the R\&D process for developing new medicines more effective and efficient. A growing number of biotechnology, medical device, and pharmaceutical companies are leveraging collaborative approaches and knowledge sharing to work with GUI. This new era requires that biopharma executives develop new managerial capabilities related to cooperation, co-opetition, flexibility, and innovation.

Via OI, the development of multidirectional relationships between large, global biopharma firms and their R\&D partners is creating long-term value in the form of new OI processes, products, structures, and tools. We noted several summary observations in this regard. First, productive OI drug development requires an open-minded culture among network participants. Second, effective OI requires a new set of specific managerial capabilities geared toward interfirm collaboration and communication. Third, biopharma executives must synergize corporate strategy and firm capabilities with the OI form of BMI. Increasingly, at least with respect to the operation of the global life sciences sector in the knowledge economy, effective management of innovation will require development of OI methods as a core competency.

\section{Acknowledgments}

The authors would like to thank the reviewers and the editor for excellent feedback and helpful insights on earlier versions of the manuscript.

\section{References}

Abdelkafi, N., Makhotin, S., \& Posselt, T. (2013). Business model innovations for electric mobility-What can be learned from existing business model patterns? International Journal of Innovation Management, 17(1), 1-41.

Alexy, O., Criscuolo, P., \& Salter, A. (2009). Does IP strategy have to cripple open innovation? MIT Sloan Management Review, 51(1), 71-77.

Asadullah, K., Busch, A., Gottwald, M., Reinke, P., \& Landeck, L. (2015). Industrial-academia collaborations for biomarkers. Nature Reviews Drug Discovery, 14(12), 805-806.

Bass, F. M. (1969). A new product growth for model consumer durables. Management Science, 15(5), 215-227.

Bayer. (2017). Retrieved October 25, 2017, from www.grants4targets.bayer.com

Biotechnology Innovation Organization, Biomedtracker, \& Amplion, Inc. (2016). Clinical development success rates, 2006-2015. Retrieved October 25, 2017, from http://bit.ly/22o5TGf?_ga=1.226529307.7 64361380

Bowen, A., \& Casadevall, A. (2015). Increasing disparities between resource inputs and outcomes, as measured by certain health deliverables, in biomedical research. Proceedings of the National Academy of Sciences, 112(36), 11335-11340. 
Carayannis, E. G., \& Campbell, D. F. (Eds.). (2006). Knowledge creation, diffusion, and use in innovation networks and knowledge clusters: A comparative systems approach across the United States, Europe, and Asia. Westport, CT: Greenwood Publishing Group.

Carayannis, E. G., \& Campbell, D. F. (2009). 'Mode 3' and 'quadruple helix': Toward a 21st century fractal innovation ecosystem. International Journal of Technology Management, $46(3 / 4)$, 201-234.

Carayannis, E. G., Del Giudice, M., \& Della Peruta, M. R. (2014). Managing the intellectual capital within government-university-industry R\&D partnerships: A framework for the engineering research centers. Journal of Intellectual Capital, 15(4), 611-630.

Carayannis, E. G., Grigoroudis, E., Sindakis, S., \& Walter, C. (2014). Business model innovation as antecedent of sustainable enterprise excellence and resilience. Journal of the Knowledge Economy, 5(3), 440-463.

Carayannis, E. G., Provance, M., \& Grigoroudis, E. (2016). Entrepreneurship ecosystems: an agent-based simulation approach. The Journal of Technology Transfer, 41(3), 631-653.

Carayannis, E. G., Sindakis, S., \& Walter, C. (2015). Business model innovation as lever of organizational sustainability. The Journal of Technology Transfer, 40(1), 85-104.

Carayannis, E. G., \& Ziemnowicz, C. (Eds.). (2007). Rediscovering Schumpeter: Creative destruction evolving into 'Mode 3.' Boston, MA: Palgrave Macmillan.

Chesbrough, H. (2003). Open innovation: The new imperative for creating and profiting from technology. Boston, MA: Harvard Business School Press.

Chesbrough, H. (2006). Open business models: How to thrive in the new innovation landscape, Boston, MA: Harvard Business School Press.

Chesbrough, H. (2010). Business model innovation: Opportunities and barriers. Long Range Planning, 43(2/3). 354-363.

Chesbrough, H., \& Bogers, M. (2014). Explicating open innovation: Clarifying an emerging paradigm for understanding innovation. In H. Chesbrough, W. Vanhaverbeke, \& J. West, (Eds.), New Frontiers in Open Innovation, (pp. 3-28). Oxford, England: Oxford University Press.

Chesbrough, H. \& Chen, E. L. (2015). Using inside-out open innovation to recover abandoned pharmaceutical compounds. Journal of Innovation Management, 3(2), 21-32.

Chesbrough, H., Vanhaverbeke, W., \& West, J. (Eds.). (2014). New frontiers in open innovation. Oxford, England: Oxford University Press.

Del Giudice, M., Caputo, F., \& Evangelista, F. (2016). How are decision systems changing? The contribution of social media to the management of decisional liquefaction. Journal of Decision Systems, 25(3), 214-226.

Del Giudice, M., \& Della Peruta, M. R. (2016). The impact of IT-based knowledge management systems on internal venturing and innovation: A structural equation modeling approach to corporate performance. Journal of Knowledge Management, 20(3), 484-498.

Del Giudice, M., Della Peruta, M. R., \& Maggioni, V. (2015). A model for the diffusion of 
knowledge sharing technologies inside private transport companies. Journal of Knowledge Management, 19(3), 611-625.

Del Giudice, M., \& Maggioni, V. (2014). Managerial practices and operative directions of knowledge management within inter-firm networks: A global view. Journal of Knowledge Management, 18(5), 841-846.

Della Peruta, M. R., \& Del Giudice, M. (2013). Knowledge accumulation and reuse for spinning off firms from learning organizations: An individual knowledge based perspective. International Journal of Social Ecology and Sustainable Development, 4(4), 20-29.

De Reuver, M., Bouwman, H., \& Haaker, T. (2013). Business model roadmapping: A practical approach to come from an existing to a desired business model. International Journal of Innovation Management, 17(1), 1-18.

Ekins, S., Waller, C. L., Bradley, M. P., Clark, A. M., \& Williams, A. J. (2013). Four disruptive strategies for removing drug discovery bottlenecks. Drug Discovery Today, 18(5/6), $265-271$.

FDA (2014). Novel New Drugs 2013 Summary. Retrieved October 25, 2017, from:

https://www.fda.gov/media/ 87579/download

FDA (2015). Novel New Drugs 2014 Summary. Retrieved October 25, 2017, from:

https://wayback.archive-it.org/7993/20170406032101/https://www.fda.gov/downloads

/Drugs/DevelopmentApprovalProcess/DrugInnovation/UCM430299.pdf

FDA (2016). Novel Drugs Summary 2015. Retrieved October 25, 2017, from:

https://www.fda.gov/drugs/new-drugs-fda-cders-new-molecular-entities-and

-new-therapeutic-biological-products/novel-drugs-summary-2015

FDA (2017). Novel Drugs Summary 2016. Retrieved October 25, 2017, from:

https://www.fda.gov/drugs/new-drugs-fda-cders-new-molecular-entities-and

-new-therapeutic-biological-products/novel-drugs-summary-2016

Freeman, J., Carroll, G. R., \& Hannan, M. T. (1983). The liability of newness: Age dependence in organizational death rates. American Sociological Review, 48(5), 692-710.

Gassmann, O., Enkel, E., \& Chesbrough, H. (2010). The future of open innovation. RESD Management, 40(3), 213-221.

Hartung, D. M., Bourdette, D. N., Ahmed, S. M., \& Whitham, R. H. (2015). The cost of multiple sclerosis drugs in the US and the pharmaceutical industry: Too big to fail? Neurology, 84(21), $2185-2192$.

Howard, D. H., Bach, P. B., Berndt, E. R., \& Conti, R. M. (2015). Pricing in the market for anticancer drugs. Journal of Economic Perspectives, 29(1), 139-162.

Howe, J. (2008). Crowdsourcing: Why the power of the crowd is driving the future of business. New York, NY: Crown Publishing Group.

InnoCentive (2017). Retrieved October 25, 2017, from https://www.innocentive.com 
Innovative Medicines Initiative (2017). Retrieved October 25, 2017, from http://www.imi. europa.eu

Johnson, M. W. (2010). Seizing the white space: Business model innovation for growth and renewal. Boston, MA: Harvard Business Press.

Landeck, L., Lessl, M., Busch, A., Gottwald, M., \& Asadullah, K. (2016). The role of open innovation in biomarker discovery. Advances in Precision Medicine, 1(2), 1-4.

Landeck, L., Lessl, M., Reischl, J., Busch, A., Carrigan, P., Gottwald, M., Reinke, P., \& Asadullah, K. (2016). Collaboration for success: The value of strategic collaborations for precision medicine and biomarker discovery. Advances in Precision Medicine, 1(1), 25-33.

Levine, S. S., \& Prietula, M. J. (2013). Open collaboration for innovation: Principles and performance. Organization Science, 25(5), 1414-1433.

Moscicki, R. A., \& Tandon, P. K. (2017). Drug-development challenges for small biopharmaceutical companies. New England Journal of Medicine, 376(5), 469-474.

Munos, B. H. (2009). Lessons from 60 years of pharmaceutical innovation. Nature Reviews Drug Discovery, 8(12), 959-968.

Munos, B. H. (2016). Biomedical innovation: Lessons from the past and perspectives for the future. Clinical Pharmacology 83 Therapeutics, 100(6), 588-590.

Munos, B. H., \& Chin, W. W. (2011). How to revive breakthrough innovation in the pharmaceutical industry. Science Translational Medicine, 3(89), 89-105.

Munos, B. H., \& Orloff, J. J. (2016). Disruptive innovation and transformation of the drug discovery and development enterprise. NAM Perspectives. Discussion Paper. National Academy of Medicine, Washington, D.C. doi: 10.31478/201607c

Nicotra, M., Romano, M., \& Del Giudice, M. (2014). The evolution dynamic of a cluster knowledge network: The role of firms' absorptive capacity. Journal of the Knowledge Economy, $5(2), 240-264$.

Niosi, J. \& McKelvey, M. (2018). Relating business model innovations and innovation cascades: The case of biotechnology. Journal of Evolutionary Economics, 28(5), 1081-1109.

Nilsson, N., \& Minssen, T. (2018). Unlocking the full potential of open innovation in the life sciences through a classification system. Drug Discovery Today, 23(4), 771-775.

Organisation for Economic Co-operation and Development (2015). Key Biotechnology Indicators. Retrieved October 25, 2017, from:

http://www.oecd.org/innovation/inno/keybiotechnologyindicators.htm

Paul, S. M., Mytelka, D. S., Dunwiddie, C. T., Persinger, C. C., Munos, B. H., Lindborg, S. R., \& Schacht, A. L. (2010). How to improve R\&D productivity: The pharmaceutical industry's grand challenge. Nature Reviews Drug Discovery, 9(3), 203-214.

Pharmaceutical Research and Manufacturers of America (2016). Retrieved October 25, 2017, from https://www.phrma.org

Procter and Gamble. (2016). Retrieved October 25, 2017, from http://www.pgconnectdevelop.com 
Quintane, E., Casselman, R. M., Sebastian, B. R., \& Nylund, P. A. (2011). Innovation as a knowledge-based outcome. Journal of Knowledge Management, 15(6), 928-947.

Robertson, M. N., Ylioja, P. M., Williamson, A. E., Woelfle, M., Robins, M., Badiola, K. A., Willis, P., Olliaro, P., Wells, T. N., \& Todd, M. H. (2014). Open source drug discovery-A limited tutorial. Parasitology, 141 (1), 148-157.

Scannell, J. W., Blanckley, A., Boldon, H., \& Warrington, B. (2012). Diagnosing the decline in pharmaceutical R\&D efficiency. Nature Reviews Drug Discovery, 11 (3), 191-200.

Schneider, S., \& Spieth, P. (2013). Business model innovation: towards an integrated future research agenda. International Journal of Innovation Management, 17(1), 1-34.

Schuhmacher, A., Germann, P., Trill, H., \& Gassmann, O. (2013). Models for open innovation in the pharmaceutical industry. Drug Discovery Today, 18(23/24), 1133-1137.

Schweizer, L., \& He, J. (2018). Guiding principles of value creation through collaborative innovation in pharmaceutical research. Drug Discovery Today, 23(2), 213-218.

Segers, J. (2015). The interplay between new technology based firms, strategic alliances and open innovation, within a regional systems of innovation context. The case of the biotechnology cluster in Belgium. Journal of Global Entrepreneurship Research, 5(1), 16.

Segers, J. (2016). Regional systems of innovation: Lessons from the biotechnology clusters in Belgium and Germany. Journal of Small Business and Entrepreneurship, 28(2). 133-149.

Shaw, D. L. (2017). Focus: Drug development: Is open science the future of drug development? The Yale Journal of Biology and Medicine, 90(1). 147-151.

Stinchcombe, A. L. (1965). Organizations and social structure. Handbook of Organizations, $44(2) .142-193$.

Thomas, D., \& Wessel, T. (2015). Emerging therapeutic company investment and deal trends. Biotechnology Industry Organization. Washington, D.C. Retrieved October 25, 2017, from https://nmbio.org/wp-content/uploads/BIO-Emerging-Therapeutic-Company-Report-June-11-2015.pdf

Toma, A., Secundo, G., \& Passiante, G. (2018). Open innovation and intellectual property strategies: Empirical evidence from a bio-pharmaceutical case study. Business Process Management Journal, 24 (2), 501 - 516.

Tufts Center for the Study of Drug Development. (2015). Outlook 2015. Boston, MA: Tufts University. Retrieved October 25, 2017 from https://csdd.tufts.edu/outlookreports

U.S. Department of Health and Human Services (2016). HHS FY2016 Budget in Brief. Retrieved October 25, 2017, from http://www.hhs.gov/about/budget/budget-in-brief/nih/index.html\#budget

Wikhamn, B. R., Wikhamn, W., \& Styhre, A. (2016). Open innovation in SMEs: A study of the Swedish bio-pharmaceutical industry. Journal of Small Business and Entrepreneurship, 28(2), 169-185. 


\section{Biographies}

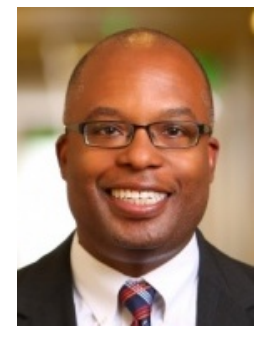

James J. Gillespie. James J. Gillespie received his $\mathrm{PhD}$ in management and organization behavior at the Northwestern University Kellogg School of Business. His education includes Carnegie Mellon University, Harvard University, Massachusetts Institute of Technology, and Princeton University. He is a Faculty Member in the Department of Business and Economics at Saint Mary's College where he focuses on international management and new ventures. His experience includes the Center for Healthcare Innovation in Chicago, the Stanford University School of Medicine's Clinical Excellence Research Center, and the Yale University School of Medicine's Center for Digital Health \& Innovation. Dr. Gillespie is coauthor of Patient-Centric Analytics in Health Care: Driving Value in Clinical Settings and Psychological Practice (Lexington Books, 2017).

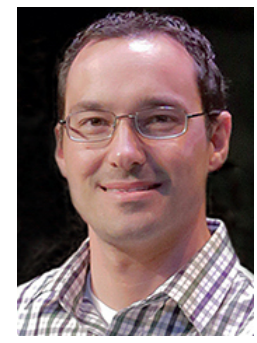

Gregory J. Privitera. Gregory J. Privitera received his $\mathrm{PhD}$ in behavioral neuroscience at the State University of New York at Buffalo in 2006 and completed his postdoctoral work at Arizona State University, Tempe, AZ. He is a Professor of Psychology at St. Bonaventure University where he is recipient of their highest teaching honor and their highest honor for research and scholarship. He is a veteran of the U.S. Marine Corps, and his research bridges knowledge creation across the areas of business and psychology. He is author of more than two dozen books and three dozen peer-reviewed articles for texts across these fields. Dr. Privitera is author of Statistics for the Behavioral Sciences (SAGE, 2017), a best-selling book in its third edition. His texts are adopted internationally at over 200 institutions including Harvard University, Stanford University, Johns Hopkins University, Columbia University, and Dartmouth.

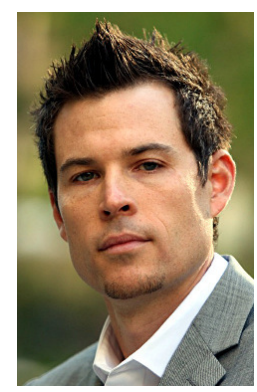

Joseph Gaspero. Joseph Gaspero is the Chief Executive Officer and Co-Founder of the Center for Healthcare Innovation, an independent, nonprofit research and educational institute dedicated to entrepreneurship and innovation in healthcare and medicine. At the Center, Mr. Gaspero leads research and education initiatives focusing on health equity, patient-driven healthcare, patient engagement, clinical trials, drug pricing, and other pressing healthcare issues. Under his leadership, several patient-focused initiatives have received grant support and funding from large corporate and philanthropic organizations. 